\title{
Chapter 1 \\ Introduction to Artificial Intelligence in Economics and Finance Theories
}

\subsection{Introduction}

The world is changing rapidly. There is no time in history when virtually every aspect, whether human life, economies or politics among other things, has been affected by the rapid change brought through by developments in information technology (Harari 2018). Technological advances have allowed humanity to discover powerful energy sources, discover faster modes of transportation for humans, goods and services, improved the speed in which we communicate, landed human beings to the moon, and there is even an attempt to send a spacecraft on a mission to the sun. Technology has allowed human beings to have a better mode of diagnosing and even curing diseases. The speed to which the COVID-19 test was developed and deployed to deal with the pandemic that engulfed the globe in the first quarter of 2020 is testimony to this. Agricultural yields have also seen an improvement, owing to technological advances. In a sense, advances in technology have enabled humanity to conquer the barriers of nature. Life has certainly improved compared to our ancestors.

In order to understand and contextualize these technological advances, Marwala and Hurwitz (2017) posit that the developments in information technology could be best characterized by the four phases of revolution in human history, namely, the first, second, third and fourth industrial revolutions (Ashton 1948; Baten 2016). Accordingly, the first industrial revolution brought mechanical innovations with the development of the steam engine, which was the key to the then industrial revolution. It was catalyzed by the scientific revolution of Isaac Newton, Robert Hooke and James Watt. The second industrial revolution started in the second half of the nineteenth century. It brought the oil-powered internal combustion engine, electricity, electric motors and electrical communication. There were major technological advances during this period, including the telephone, light bulbs, phonograph, the assembly line and mass production of goods and services.

The third industrial revolution or digital revolution came in the 1950s; it brought computerization, which included the mainframe computers, personal computers 
(PCs) and the Internet, and the information and communication technology (ICT) that we continue to use today. This industrial revolution was catalyzed by the invention of the transistor. The period is characterized by the advancement of technology from analog electronic and mechanical devices to the digital technology (Agrawal et al. 2018; Marwala and Hurwitz 2017).

The fourth industrial revolution arrived at the beginning of the twenty-first century. This revolution brought with it the advent of cyber-physical systems, which represent a new way in which technology becomes embedded within societies, i.e. business, government, civil society, etc., and the human body. Further, it is driven by the rapid convergence of advanced technologies across the biological, physical and digital worlds. The fourth industrial revolution is manifested by emerging technology breakthroughs in a number of fields, which include, among others, robotics, AI, biotechnology, 3D printing, advanced materials such as graphene, "Internet of Things (IoT)" and blockchain (Harari 2018; Agrawal et al. 2018; Marwala and Hurwitz 2017).

Looking at these revolutions, it is clear that they have had unique impacts on every aspect of human life, including business. Of interest though is that literature has not attempted to utilize these advances in technology to modernize economics and finance theories that are fundamental in the decision-making process for the purpose of allocating scarce resources among other things. With the simulated intelligence in machines, which allows machines to act like humans and to some extent even anticipate events better than humans, thanks to their ability to handle massive data sets, this book uses artificial intelligence to explain what these economics and finance theories mean in the context of an agent wanting to make a decision.

It is apparent that in the fourth industrial revolution, technology in general will continue to have an unprecedented role. Marwala and Hurwitz (2017) support this view; however, within the technology space, they specifically single out AI. They argue that the fourth industrial revolution is embedded on AI. Perhaps the reason they would have adopted this stance is that, nowadays, AI is everywhere. Agrawal et al. (2018) point out that $\mathrm{AI}$ is in "our phones, cars, shopping experiences, romantic matchmaking, hospitals, banks and all over in the media".

\subsection{Artificial Intelligence}

Artificial intelligence is a technique that is used to make computers intelligent (Marwala 2007, 2009). There are three types of artificial intelligence, and these are machine learning, computational intelligence and soft computing (Marwala 2009). Computational intelligence is the use of intelligent biological systems such as the flocking of birds or the colony of ants to build intelligent machines. Computational intelligence has been used successfully to create systems such as Google Maps that identify the shortest distances between two points (Marwala 2012). For an example, a population of ants, shown in Fig. 1.1, is able to build complicated anthills, shown in Fig. 1.2. What sort of economics have these ants imagined in order to be able to build 


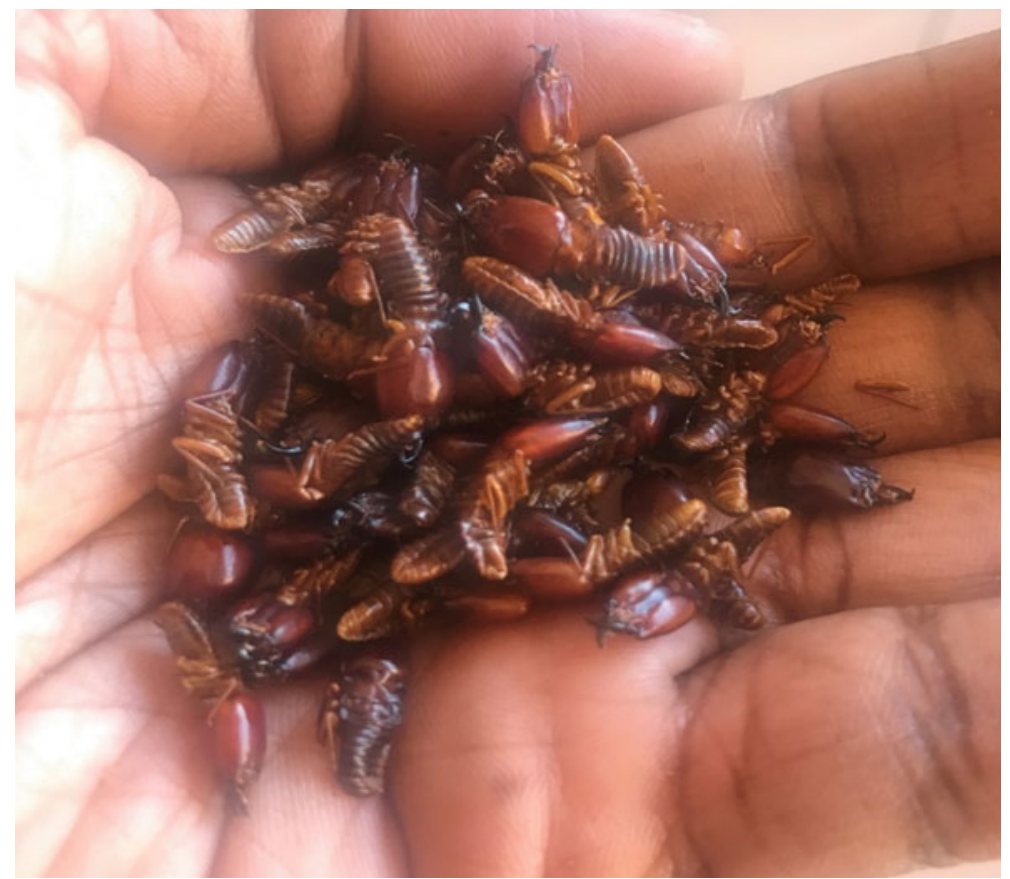

Fig. 1.1 Ants, which are able to build complicated structures such as the one illustrated in Fig. 1.2

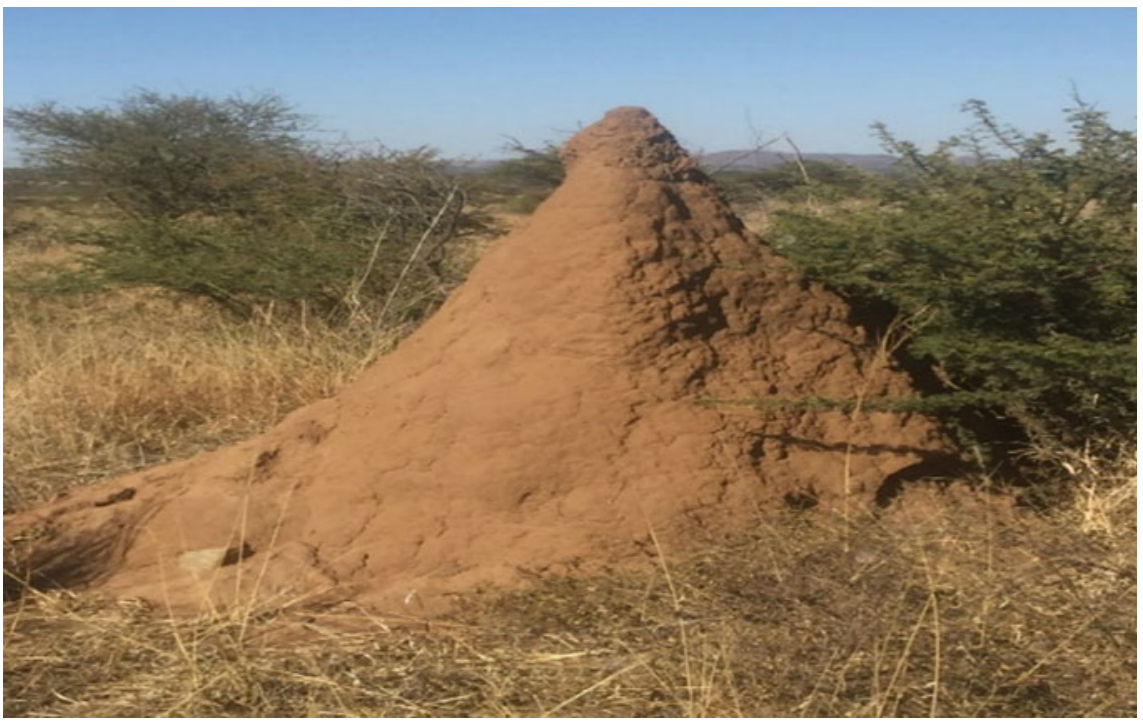

Fig. 1.2 An anthill built by ants, such as the ones illustrated in Fig. 1.1 
assets such as these? These ants have two mechanisms of building such a complicated economy, and these are: group intelligence and individual intelligence. In essence, what this means is that on its own (individual intelligence), the ant will struggle to put together such a structure, but collectively these ants are able to put together this complicated economy. This book studies how the rise of artificial intelligence would impact the economics and finance theories.

Soft computing does not require large amounts of data to train (Marwala and Lagazio 2011). One example of soft computing is fuzzy logic. Fuzzy logic uses possibility rather than probability models to create an inference system. Fuzzy logic is able to model difficult variables, such as linguistic variables. Fuzzy logic has been used to model many complex systems, including financial instruments (Patel and Marwala 2006).

Machine learning is the statistical approach to making intelligent machines. One example of machine learning is a neural network. Neural network is based on the functioning of the human brain through neurons and how they fire electrical signals to transmit information. An illustration of a neural network is shown in Fig. 1.3. It is worth noting that neural networks have been successful in modelling complex systems (Marwala 2018).

An example of machine learning is deep learning, which requires huge amounts of data to train (Leke and Marwala 2019). It is called deep learning because it has many hidden layers. Deep learning has been very successful for problems such as face recognition and voice recognition. For instance, deep learning is used when a person loads photos on Facebook, and this application automatically identifies and labels the names of the people on the photos. Because deep learning depends so much on data, it is making data emerge as the most valuable commodity, thereby arguably surpassing oil.

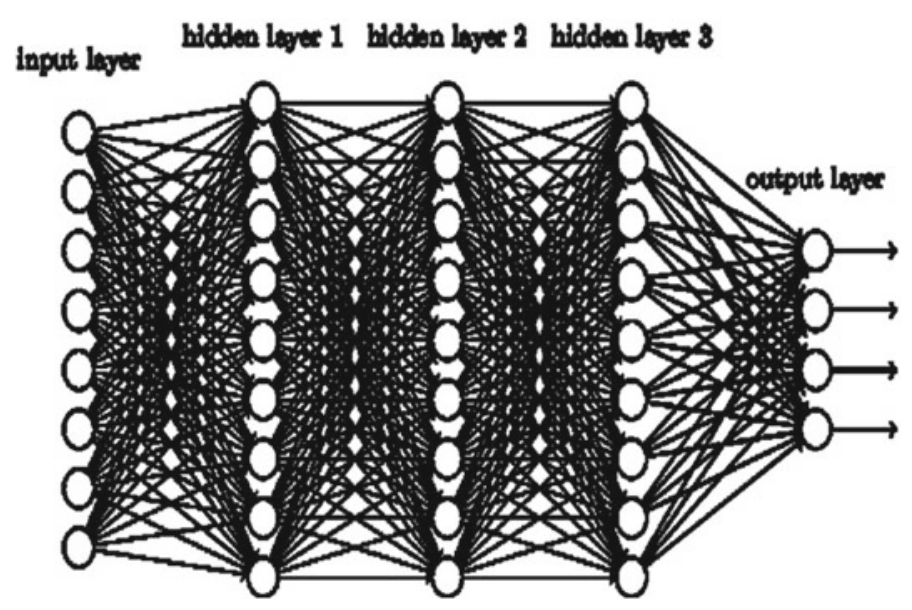

Fig. 1.3 An example of a deep neural network 
It has been established that artificial intelligence can be used effectively as a prediction tool. In their attempt to clear future uncertainties so that sound decisions can be made, agents use predictions as an input into the decision-making process, where economics and finance theories would have provided a framework in which agents make decisions on how to allocate scarce resources (Marwala 2013, 2014, 2015).

As AI seizes all aspects of human life, there is a fundamental shift in the way in which humans are thinking of and doing things. Ordinarily, humans have relied on economics and finance theories to make sense of, and predict, concepts such as comparative advantage, long-run economic growth, lack or distortion of information and failures, role of labour as a factor of production and the decision-making process for the purpose of allocating resources among other theories.

The main feature of these theories is that they try to eliminate the effects of uncertainties by attempting to bring the future to the present. The fundamentals of this statement are deeply rooted in risk and risk management. Standard number 31000 of the International Standardisation Organisation (ISO) defines risk as "the effect of uncertainty on the objective". In other words, uncertainties are the main component of the deviations from the expected outcomes (Moloi 2016).

In behavioural sciences, economics as a discipline has always provided a wellestablished foundation for understanding uncertainties and what this means for decision-making (Agrawal et al. 2018). Economics has done this through different models that attempt to predict the future. On its part, risk management attempts to hedge or mitigate these uncertainties in order for "the planner" to reach the favourable outcome.

As explained earlier, the main feature of economic theories is that they try to eliminate the effects of uncertainties by attempting to bring the future to the present. Agrawal et al. (2018) have argued that AI (at least as it is right now) "does not actually bring us intelligence, but a critical component of intelligence-prediction". This is what humans have in the past deployed economics and financial theories to do.

With AI providing us with a critical component of intelligence, the manner in which economics and finance theories have been presented is impacted. This book focuses on how artificial intelligence is to redefine certain important economics and financial theories that, for a number of years have specifically been used for the purpose of eliminating uncertainties to allow agents to make informed decisions.

\subsection{Finance and Economics}

Society has evolved over the years, and one of the most interesting inventions is money. Money was invented somewhere in the Middle East. When society moved to the agricultural age, there was a problem that agricultural production was not consistent and, therefore, there was need to store food for the times of drought. The place where this storage happened was in the churches. The priests received food to store and in exchange gave a token (money). Societies are organized along the lines of 
money. The whole class system was fundamentally about money. The exchange of goods and services, usually using money, is what we call the economy. The dynamics of money in society is what we call finance. On understanding the economy and money, various models and theories were developed. Many of these models were not universally accepted, and, sometimes, schools of thoughts evolved along political ideological lines. In the United States, the Republicans and the Democrats are divided along the economic line. The democrats believe in what is called the demand-side economics where an economy can be stimulated to encourage aggregate demand. This is what Adam Smith called the invisible hand (Smith 2015). The Republicans, on the other hand, believe in the supply-side economics where they believe in deregulation and a limited hand in the economy; in other words, Republicans advocate for lesser government intervention in the economy.

Several theories emerged and Marwala and Hurwitz's (2017) study was on how these theories are influenced by the advances in AI. For example, they studied the laws of demand and supply and observed that advances in AI are making the principles of demand and supply more individualized, leading to individualized pricing (Mankiw and Taylor 2011). They also studied the theory of rational expectations, which prescribes that on predicting the future, agents are not systematically wrong (Muth 1961). Marwala and Hurwitz (2017) observed that the advances of AI make the theory of rational expectations more valid. When rational agents operate in the market, they do so in order to maximize their utility. The economic theory on the maximization of utility is called rational choice. Rational choice is based on the philosophical concept called utilitarianism (Friedman 1996; Mill 2001). Research has shown that it is impossible for agents to be rational. The best agents can do is to be bounded rationally. Marwala and Hurwitz (2017) observed that AI and related technologies make the bounds of rationality flexible. It turns out that if such agents are people, they never maximize utility because doing so is a risky strategy and people have evolved to be risk averse. This is called prospect theory (Kahneman and Tversky 1979). Marwala and Hurwitz (2017) observed that the bounds of rationality are better off when agents are machines than when agents are human beings.

Another economic theory is information asymmetry. Information asymmetry is a situation where the buyers and sellers of goods have unequal information (Stigler 1961; Spence 1973; Aboody and Lev 2000). In such a situation, the markets are inefficient. Marwala and Hurwitz (2017) have observed that the use of AI makes the markets more symmetrical and, therefore, improves market efficiency. Game theory is a mathematical technique that is used to understand the dynamics of a situation where agents interact. In game theory, agents interact under certain rules until they reach the Nash equilibrium (Osborne and Rubinstein 1994). Unfortunately, the mathematics works well for interactions with fewer agents. AI is able to expand the number of agents that can interact in a simulation. The reverse of game theory is called mechanism design. While in game theory, we study the interactions of agents under some set of rules until they achieve Nash equilibrium (Nash 1950), in mechanism design we have agents and know the desired Nash equilibrium and all we want to identify are the rules that will make that possible (Myerson and Satterthwaite 1983). Mechanism design has been used for market design, incentive design and in 
the kidney exchange market. Marwala and Hurwitz (2017) used AI to implement mechanism design.

Portfolio theory is a process of pooling financial assets together to minimize risk (Markowitz 1952). How these assets are pooled together is an optimization problem. Markowitz (1952) proposed a model that works well for stationary environments. Marwala and Hurwitz (2017) proposed the use of AI for portfolio optimization in a non-stationary environment. AI makes markets efficient, thereby improving the validity of the efficient market hypothesis (Fama 1996, 2008). This book extends the impact of AI in economics and finance to the theories that are described in the themes of the book presented below.

\subsection{Themes of the Book}

Chapter 2 of this book examines the Solow Theory (Solow 1956; Swan 1956). The theory postulates that growth of per-capita output is the result of capital accumulation and/or technological progress. In essence, what it says is that as the economy reaches its steady state (equilibrium), per-capita output growth is only possible through the technological progress, taking into account that technological progress is exogenous in the model. This chapter examines the tenets of the Solow Theory, focusing on the main assumptions and how the theory is applied in economics. The manner in which the application of AI would affect assumptions and how the theory is applied are also discussed. Conclusions are drawn on how the theory could be modernized, given the effect of AI.

Chapter 3 looks at the Ricardian Theory (Dornbusch et al. 1977). The theory assumed two countries, producing two goods that are homogeneous across countries and firms within an industry. In this theory, labour is the main factor of production, mobile within the country's industries but cannot move abroad. Labour is also homogeneous within a country; however, this may be different across countries. The implication of homogeneous labour within a country with differences between countries implies that the production technology could be different between two trading nations. Technological advances have turned the world into a global village. In essence, the borders have essentially been flattened. AI will change the very nature of the Ricardian Theory in the sense that, as it evolves, AI flattens the borders and possibly reduces reliance on labour. For instance, one information technology specialist can give guidance on how the application works over the Internet from wherever they are in the world; doctors can perform virtual life-saving operations, and professors now can give virtual classes.

Chapter 4 pays attention to the Dual-Sector economic theory. At a high level, this theory supposes that the economy can be divided into two parts: the developed and the underdeveloped. In the two sectors, labour can be migrated from the underdeveloped sector to the developed sector until it makes no more economic sense to do so, and this is called the Lewis turning point. In the era of AI, this framework can be used to 
study the migration of labour from humans to machines until it makes no-sense to continue doing so, thereby reaching the Lewis-Automation turning point.

Chapter 5 looks at the Dynamic Inconsistency theory, which reflects a changing nature of human beings' preferences over time that could result in these preferences differing at some point in the preference continuum, yielding the inconsistencies. This means that not all selected preferences are aligned, and that there is a misalignment somewhere in the preference continuum (Simaan and Cruz 1973). With the ability to store the information, learn about the previous behaviour of the agent and possibly pre-empt the next move that the agent is likely to take, while also providing basket options, AI would awaken the subconscious mind of the agent, challenging the notion of Dynamic Inconsistency with that of an informed choice.

Chapter 6 is dedicated to the Phillips Curve. This theory states that inflation and unemployment have a stable and inverse relationship (Phillips 1958). In this theory, economic growth is expected to generate inflation and more work opportunities, which decreases unemployment. This chapter examines these tenets, focusing on the main assumptions. The manner in which the application of AI would impact on these assumptions and the potential impact of AI on this theory are discussed. In particular, our focus is on employment. In the automated world, economic growth could be fuelled by robotic infrastructure. Because individuals would possibly have been replaced by the robotic infrastructure, growth would not be accompanied by employment opportunities. At the same time, since this could result in unemployment, the demand for goods and services could be expected to be put under pressure. If supply remains the same because robotic infrastructure will be producing potentially at a higher rate than humans, prices could be expected to decline, dampening inflation prospects.

Chapter 7 looks at the Laffer Curve (Gahvari 1989). It examines the tenets of the Laffer Curve, which defines the relationship between tax revenue and the tax rate. We study the impact of the advances in automation and its impact on tax collection. In particular, we study how advances in AI are changing the very nature of the Laffer Curve.

Chapter 8 attends to the theory of Adverse Selection. Economics, risk management and insurance are disciplines that employ both the concepts of moral hazard and adverse selection (Akerlof 1970). Adverse selection occurs when one agent in a transaction has more information than the other party, thus enjoying an advantage. Since most information in a market-driven economy is transmitted through pricing, adverse selection will result in unfair pricing of goods and services and the unfair advantage on the part of the agent with more information. This chapter examines how the Adverse Selection theory will look like in a situation where the information is digitally and easily accessible by all parties in the transaction. The modern world is highly characterized by digitization, which ensures access to more information about the counterparty in the transaction. This will change the very nature of the Adverse Selection theory.

Chapter 9 focuses on the Moral Hazard theory (Arrow 1963). Moral hazard occurs when the agent behaves in a manner that they would not have behaved had they not put mitigating circumstances in place. In insurance contracts, for instance, 
an agent would put themselves in a risky situation because they know that they are insured. This exposes the insurer. Alternatively, in financing transactions, one agent would not enter into the contract in good faith, i.e. they would have provided misleading information about its assets, liabilities or credit-bearing capacity. Similar to the Adverse Selection theory, this chapter examines how the Moral Hazard theory changes in a situation where the information is digitally and easily accessible by all parties in the transaction. The modern world is highly characterized by digitization, which ensures access to more information about the counterparty in the transaction. This changes the very nature of the Adverse Selection theory.

Chapter 10 examines the Creative Destruction Theory (Reinert and Reinert 2006). This theory was derived from the work of Karl Marx by Joseph Schumpeter. As technology improves, a "gale of creative destruction" is unleashed through the process of industrial mutation, where the economic structure is revolutionized without much intervention of the external forces. In the process of this revolution, old technologies are destroyed and new ones are created. We examine whether the creative destruction is a result of human inefficiencies, for instance, the lack of data, the inability to store crucial data, the inability to get insights on the data so as to learn about the previous behaviour of the agent and which of these factors hinders the owners of the destructed technology to pre-empt the next move that the agent is likely to take, while also providing basket options so that their technology remains relevant and moves with time. With the ability to store the information, learn about the previous behaviour of the agent and possibly pre-empt the next move that the agent is likely to take, while also providing basket options, AI would provide current technology holders with vital intelligence to remain competitive, relevant and timely, thus challenging the notion of Creative Destruction as it is presented with that of the Creative Modernisation.

Chapter 11 examines the Agency Theory. The Agency theory was developed by Jensen and Meckling (1976). According To Kopp (2019), the agency theory is a principle utilized in an attempt to explain the complex relationship that exists between the owners (principal) and managers (agents) of the business. Jensen and Meckling (1976) define the agency relationship as a form of contract between a company's owners and its managers, where the owners (as principal) appoint an agent (the managers) to manage the company on their behalf. This relationship is most commonly found between shareholders as principals and company executives as agents. Other similar relationships are found between financial planners and portfolio managers acting as agents on behalf of their clients, the investors, acting as principals, and a lessee acting as an agent on behalf of the lessor, and the property owner acting as the principal among others.

Chapter 12 examines the Legitimacy. Theory and the Legitimacy Gap. According to Guthrie and Ward (2006), the Legitimacy theory is derived from the concept of organizational legitimacy. Legitimacy is considered by Suchman (1995) as a generalized perception that the actions of an organisation are desirable and appropriate within some socially constructed system of norms, values, beliefs and definitions.

Chapter 13 provides a synopsis of each theory that was considered. 


\subsection{Key Points}

Advances in technology have enabled humanity to conquer the barriers of nature. Life has certainly improved compared to our ancestors.

- Existing literature has not attempted to utilize advances in technology to modernize economics and finance theories that are fundamental in the decision-making process for the purpose of allocating scarce resources among other things. The main feature of economic theories is that they try to eliminate the effects of uncertainties by attempting to bring the future to the present.

- As AI provides us with a critical component of intelligence, the manner in which economics and finance theories have been presented will be impacted. This book focuses on how artificial intelligence redefines certain important economics and financial theories that are used for purposes of eliminating uncertainties so as to allow agents to make informed decisions.

- With the simulated intelligence in machines, which allows machines to act like humans and, to some extent, even anticipate events better than humans, thanks to their ability to handle massive data sets, this book uses artificial intelligence to explain what these economics and financial theories mean in the context of the agent wanting to make a decision.

\section{References}

Aboody D, Lev B (2000) Information asymmetry, R\&D, and insider gains. J Financ 55(6):2747_ 2766

Agrawal A, Gans J, Goldfarb A (2018) Prediction machines: the simple economics of artificial intelligence. Harvard Business Review Press

Akerlof GA (1970) The market for 'memons': quality uncertainty and the market mechanism. Q J Econ 84(3):488-500

Arrow K (1963) Uncertainty and the welfare economics of medical care. Am Econ Rev 53(5):941973

Ashton TS (1948) The industrial revolution (1760-1830). Oxford University Press, Oxford

Baten J (2016) A history of the global economy: from 1500 to the present. Cambridge University Press, Cambridge

Dornbusch R, Fischer S, Samuelson P (1977) Comparative advantage, trade and payments in a Ricardian Model with a Continuum of Goods. Am Econ Rev 67(5):823-839

Fama EFK (1996) Multifactor explanation of asset pricing anomalies. Journal of Finance 51(1):5584. https://doi.org/10.1111/j.1540-6261.1996.tb05202.x

Fama EFK (2008) Dissecting anomalies. J Financ 63(4):1653-1678. https://doi.org/10.1111/j.15406261.2008.01371.x.F

Friedman J (1996) The rational choice controversy. Yale University Press, New Haven

Gahvari F (1989) The nature of government expenditures and the shape of the Laffer curve. J Public Econ 40(2):251-260

Harari YN (2018) 21 Lessons for the 21st century. Jonathan Cape, London

Jensen MC, Meckling WH (1976) Theory of the firm: managerial behavior, agency costs and ownership structure. In: Jensen MC (ed) A theory of the firm: governance, residual claims and 
organizational forms (December 2000). Harvard University Press. Available at SSRN https://ssrn. com/abstract=94043 or http://dx.doi.org/10.2139/ssrn.94043 (Journal of Financial Economics (JFE), Vol. 3, No. 4, 1976)

Kopp CM (2019) Agency theory. Available from https://www.investopedia.com/terms/a/ agencytheory.asp

Kahneman D, Tversky A (1979) Prospect theory: an analysis of decision under risk. Econometrica 47(2):263

Leke CA, Marwala T (2019) Deep learning and missing data in engineering systems. Springer, London

Mankiw NG, Taylor MP (2011) Economics (2nd ed, revised ed). Cengage Learning, Andover

Markowitz HM (1952) Portfolio Selection. J Financ 7(1):77-91

Marwala T (2018) Handbook of machine learning: foundation of artificial intelligence. World Scientific Publication

Marwala T, Hurwitz E (2017) Artificial intelligence and economic theory: skynet in the market. Springer International Publishing

Marwala T (2015) Causality, correlation, and artificial intelligence for rational decision making. World Scientific, Singapore

Marwala T (2014) Artificial intelligence techniques for rational decision making. Springer, Heidelberg

Marwala T (2013) Economic modeling using artificial intelligence methods. Springer, Heidelberg

Marwala T (2012) Condition monitoring using computational intelligence methods. Springer, Heidelberg

Marwala T, Lagazio M (2011) Militarized conflict modeling using computational intelligence. Springer, Translated into Chinese by the National Defence Industry Press, Heidelberg

Marwala T (2009) Computational intelligence for missing data imputation, estimation, and management: knowledge optimization techniques. IGI Global, PA

Marwala T (2007) Computational intelligence for modelling complex systems. Research India Publications, Delhi

Mill JS (2001) Utilitarianism and the 1868 speech on capital punishment. Hackett Publishing Company, Indianapolis/Cambridge

Moloi T (2016) A cross sectoral comparison of risk management practices in South African organizations. Probl Perspect Manag 14(3):99-106

Muth JF (1961) Rational expectations and the theory of price movements. Econometrica 29(3):315335

Myerson RB, Satterthwaite MA (1983) Efficient mechanisms for bilateral trading. J Econ Theory 29(2):265-281

Nash J (1950) Equilibrium points in n-person games. Proc Natl Acad Sci 36(1):48-49

Osborne MJ, Rubinstein A (1994) A course in game theory. MIT Press, Boston, MA

Patel P, Marwala T (2006) Neural networks, fuzzy inference systems and adaptive-neuro fuzzy inference systems for financial decision making. Lecture notes in computer science, vol 4234. Springer, Berlin, Heidelberg, pp 430-439

Phillips AW (1958) The relation between unemployment and the rate of change of money wage rates in the United Kingdom, 1861-1957. Economica New Ser 25(100):283-299

Reinert H, Reinert ES (2006) Creative destruction in economics: Nietzsche, Sombart, Schumpeter. Eur Herit Econ Soc Sci 3:55-85

Simaan M, Cruz JB Jr (1973) On the stackelberg strategy in nonzero-sum games. J Optim Theory Appl 11(5):533-555

Smith A (2015) The wealth of nations: a translation into modern English. Industrial systems research, Machester, England

Solow RM (1956) A contribution to the theory of economic growth. Q J Econ 70(1):65-94 
Spence M (1973) Job market signaling. Q J Econ 87(3):355-374. MIT Press

Stigler GJ (1961) The economics of information. J Polit Econ 69(3):213-225

Suchman M (1995) Managing legitimacy: strategic and institutional approaches. Acad Manag Rev 20(3):571-611

Swan TW (1956) Economic growth and capital accumulation. Econ Rec 32(2):334-361 